\title{
ГУМАНИТАРНЫЕ АСПЕКТЫ СОТРУДНИЧЕСТВА РОССИИ И АЗЕРБАЙДЖАНА В ХХІ ВЕКЕ
}

\section{HUMANITARIAN ASPECTS OF COOPERATION BETWEEN RUSSIA AND AZERBAIJAN IN THE 21st CENTURY}

\author{
М.Ю. Бородина, О.С. Гасанов \\ M.U. Borodina, O.S. Gasanov \\ Национальный исследовательский Нижегородский государственный университет \\ им. Н.И. Лобачевского, \\ Россия, 603950, г. Нижний Новгород, пр. Гагарина, 23 \\ National Research Lobachevsky State University of Nizhni Novgorod, \\ 23 Gagarin Avenue, Nizhny Novgorod, 603950, Russia \\ E-mail: borodina.m-u@yandex.ru, orhan2012@bk.ru
}

\begin{abstract}
Аннотация. Предметом исследования являются гуманитарные аспекты российско-азербайджанских отношений в XXI веке. В данной работе авторами было осуществлено исследование важных сфер сотрудничества между странами, а именно в культуре, науке и образовании оказывающих влияние на внешнюю политику России и Азербайджана. Кроме того, в исследовании дается оценка на состояние отношений между странами после распада СССР. В работе использовались такие методы, как анализ, обобщение, сравнительный анализ как главные методы исследования основных направлений внешнеполитической деятельности стран и принцип объективности, позволяющий установить главное направление в отношениях между странами в гуманитарной сфере. В указанной работе оценивались итоговые договоренности в сфере гуманитарного сотрудничества. Результаты исследования дают понять, что начиная с двухтысячных годов Россия и Азербайджан выходят на новый уровень стратегического сотрудничества. Одно из ключевых условий в развитии сотрудничества между странами заключается во взаимных визитах представителей двух стран на самом высшем уровне в духе стратегического партнерства. Таким образом, можно уверенно сказать, что у сторон имеются отличные перспективы для будущего развития межгосударственных отношений в гуманитарной сфере с учетом наличия современных вызовов в формировании гуманитарной политики двух стран.
\end{abstract}

\begin{abstract}
Abstact. The subject of the study is the humanitarian aspects of Russian-Azerbaijani relations in the 21st century. In this work, the authors carried out a study of important areas of cooperation between countries, namely, in culture, science and education that influence the foreign policy of Russia and Azerbaijan. In addition, the study assesses the state of relations between countries after the collapse of the USSR. In the work, such methods were used as: analysis, generalization, comparative analysis, as the main method for studying the main foreign policy activities of countries and the principle of objectivity, which allows establishing the main direction in relations between countries in the humanitarian sphere. In this work, the final agreements in the field of humanitarian cooperation were evaluated. The results of the study make it clear that since the 2000s, Russia and Azerbaijan have reached a new level of strategic cooperation. One of the key conditions in the development of cooperation between the countries is the mutual visits of representatives of the two countries at the highest level, in the spirit of strategic partnership. Thus, we can confidently say that the parties have excellent prospects for the future development of interstate relations in the humanitarian sphere, taking into account the presence of modern challenges in shaping the humanitarian policy of the two countries.
\end{abstract}


Ключевые слова: Россия, Азербайджан, гуманитарные отношения, культурные взаимосвязи, научная деятельность, студенческий обмен, международное сотрудничество, инновационные проекты.

Key words: Russia, Azerbaijan, humanitarian relations, cultural relations, scientific activitiesstudent exchanges, international cooperation, innovative projects.

Историю гуманитарных связей России и Азербайджана можно рассматривать с официального момента установления дипломатических отношений 4 апреля 1992 года, имея в виду при этом общую историю СССР и Российской империи, в рамках которых город Баку выделялся как крупный культурный и исторический центр Закавказья. Наличие вековых тесных экономических связей, взаимозависимость, а также необходимость обеспечения безопасности обусловили объединение большей части союзных республик в СНГ, членом которого является современный Азербайджан [Воронина, 2011, с. 112-121].

Не теряя исторического интереса к культуре, науке и образованию в современном мире, Азербайджан активно участвует в организации на уровне государств международных мероприятий и конференций [Алиева, Мамедова, 2016, с. 150-152].

Важнейшим документом договорно-правовой базы межгосударственных отношений России и Азербайджана стал Договор о дружбе, сотрудничестве и взаимной безопасности, который государства подписали 3 июля 1997 года.

Вопросы экономического и геополитического сотрудничества России и Азербайджана всегда актуальны и с различных сторон исследуются многими авторами, в то же время анализу гуманитарных взаимоотношений уделяется меньше внимания [Алиев, 2008, с. 22-27; Алиев, 2017, с. 10-12; Мустафаева, 2015, с. 99-101].

Российско-азербайджанские отношения носят поступательный, всеобъемлющий и углубленный характер. Постоянные взаимные деловые вояжи представителей высших органов власти стран лишь подчеркивают и укрепляют межгосударственные связи и гуманитарные аспекты сотрудничества двух стран, укрепляют культурные связи, выводя их на новый уровень.

Российско-азербайджанские культурные связи имеют действительно всеобъемлющий характер, выстроены на соседстве двух государств и коммуникациях двух народов не только в новейшее время, но и в исторической ретроспективе. Для укрепления и усиления данных взаимосвязей необходимо всегда проводить анализ, чтобы определить наиважнейшие направления их развития.

Азербайджанская и российская диаспоры в России и Азербайджане соответственно являются крупнейшими. Численность русского населения в Азербайджане на 2015 год составила 120 тысяч человек или $1,25 \%$ от общего населения страны, что являлось самым большим показателем на Южном и Северном Кавказе России. Тем временем численность азербайджанцев в России, согласно данным, указанным в источнике [Национальный состав России, 2017], в 2010 году официально составила 603070 человек или 0,4 \% от общей численности населения страны. Так же стоит отметить, что численность азербайджанской диаспоры в России продолжает официально увеличиваться. По данным Росстата за 2019 год, в страну въехало безвозвратно 8737 человек. Представленные данные непосредственно говорят о необходимости укрепления культурных связей с целью улучшения взаимопонимания и мира между государствами и их диаспорами [Алиева, 2015, с. 64-68].

Укрепление культурных связей между странами всегда начинаются с элементарных человеческих отношений, но официальность этим наиважнейшим видам взаимоотношений присваивают, конечно, главы государств, согласовывая необходимые документы во время обоюдных визитов, форумов. Одним из значимых документов, выводящих формат социального сотрудничества на новый уровень, является Декларация о дружбе и стратегическом партнерстве между Азербайджанской Республикой и Российской Федерацией, которая была утверждена 3 июля 2008 года главами государств И. Алиевым и Д. Медве- 
девым в Баку. В соответствии с Декларацией определяются следующие направления взаимодействия:

- на основе исторически значимой роли общин двух народов в Азербайджане и России создавать благоприятные условия для всестороннего развития азербайджанской и российской диаспор в сфере языка, культуры, религии, быта;

- способствовать прогрессу разносторонних взаимоотношений молодежных и студенческих организаций, научных и культурных сфер на межгосударственном уровне;

- в целях поддержания и расширения гуманитарных связей между странами, оказывать всестороннюю поддержку в вопросе создания и популяризации кафедр азербайджанского языка, истории, литературы и т. п. в ведущих российских вузах при активной поддержке азербайджанской стороны;

- при активной государственной поддержке способствовать осуществлению всесторонней деятельности филиалов МГУ им. М.В. Ломоносова в городе Баку, а также Азербайджанского государственного экономического университета в городе Дербент [Декларация о дружбе и стратегическом партнерстве между Азербайджанской Республикой и Российской Федерацией, 2008].

Для анализа обширности взаимосвязей отношений двух государств необходимо проанализировать научную сферу межгосударственных связей [Мирзазаде, 2018, с. 52-55; Мустафаева, 2016, с. 184-195]. Несмотря на богатое и емкое наследие советского времени в истории азербайджанского народа, Азербайджан сегодня независимая республика, в которой государственным языком официально является только азербайджанский, но при этом в этой стране продолжают уважительно относиться к русскому языку и проводить политику сохранения и популяризации его среди населения страны как самого перспективного на уровне иностранного языка. Тем не менее приоритетность языка над другими обуславливается и количеством учебных заведений, способных в Азербайджане преподавать русский язык на высоком уровне. Так, с момента провозглашения независимости Азербайджана и по сегодняшний день в стране действует более чем 300 школ (6\%), 18 вузов и 38 средних специальных учебных заведений. Отдельно стоит отметить действующие на территории Азербайджана Бакинский филиал Академии права и управления, Бакинский филиал Южно-Российского гуманитарного института, Бакинский филиал Московского государственного открытого университета, филиал Дагестанского государственного университета, филиал Санкт-Петербургского института внешнеэкономических связей, экономики и права, а также филиал Московского государственного университета имени М.B. Ломоносова [Rahim Rahimov, 2018]. Отдельно стоит отметить высокую оценку, данную председателем Русской общины Азербайджана Михаилом Забелиным: «У нас не закрыта ни одна русская школа. Газет и журналов на русском языке стало выходить даже больше, чем в советское время».

В России же при многочисленной азербайджанской диаспоре действуют средняя общеобразовательная школа № 157 с этнокультурным азербайджанским компонентом в г. Москве, школа № 1583 имени К.А. Керимова в г. Москве и школа № 71 в Республике Дагестан, а также 2 вуза [Рыжов, Гасанов, 2017].

В политике двух стран ведется обширная программа наращивания и популяризации культурных связей между регионами России и Азербайджана, для этого ежегодно проводятся крупные мероприятия, направленные в первую очередь на укрепление братских связей народов, тем более что азербайджанская культура близка многим мусульманским регионам страны, а также интересна в плане изучения развития в других регионах России, с которыми ее связывают теплые и дружеские отношения. Культура в истории Азербайджана занимала всегда одно из главных мест [Агабалаева, 2018, с. 58-62; Адыгезалов, 2008, с. 70-75]. Еще в советское время республика, несмотря на преимущественное мусульманское население шиитского направления, славилась удивительным гостеприимством, добрососедством и мультикультурным составом. В стране проживают представители разных религиозных конфессий. Они не испытывают какие-либо проблемы с государством или 
другими гражданами страны. Из крупных конфессий стоит выделить традиционно еврейские и русские поселения страны. Забота государства в вопросе сохранения культуры данных народов видна не только самим гражданам страны, но и высокопоставленным гостям страны, как, например, лидеру партии ЛДПР, депутату Государственной Думы Российской Федерации В.В. Жириновскому, ярому защитнику русского мира. Во время своего визита в Азербайджан в 2014 году он был крайне удивлен политикой Азербайджана, которой он не видит в других странах - союзниках России, в частности, на прессконференции депутат отметил: «Такого внимания к русскому языку, такого большого количества русских школ, отделений и факультетов в вузах нет ни в одной другой бывшей советской республике, поэтому, как ни возьми какую-то характеристику Азербайджана, в основном только положительное, я не могу найти что-то отрицательное, чтобы что-то нас не устраивало, нет этого ничего, только положительное» [Визит В.В. Жириновского в Баку, 2014]. Примечательны были и слова депутата на вопрос учеников бакинской школы № 23 после посещённых им уроков русского языка и литературы о былых своих негативных высказываниях об Азербайджане как о проблеме недопонимания, малоинформированности, он пообещал впредь защищать и поддерживать азербайджанцев за их доброе и теплое отношение к русскому народу. Стоит отметить, что сегодня В.В. Жириновский прикладывает немало усилий, чтобы укрепить и улучшить двухсторонние отношения, и не упускает возможность рассказывать о добрых и близких отношениях двух государств на самом высоком уровне.

За последние годы действительно было много насыщенных событий в плане взаимных культурных программ, которые помогали улучшить и укрепить связи в других сферах взаимных интересов. Так, в мае 2016 года в столице Азербайджана городе Баку прошли дни дагестанской культуры с непосредственным участием официальной делегации России из Республики Дагестан [Trand, 2016]. На мероприятиях были продемонстрированы выставки, музыкальные и театральные представления, а также рассказано об экономических достижениях Дагестана. Гостей пригласили к участию в инвестиционных проектах и туристическом потенциале региона России. Мероприятия проходили в присутствии главы Республики Дагестан Рамазана Абдулатипова, который, в свою очередь, с радостью встретился с соотечественниками, проживающими в Азербайджане. Во время диалога с официальными лицами Азербайджана были заложены такие проекты, как создание газет, журналов, учебных пособий на языках двух республик, а также выделении квот для дагестанских учеников в азербайджанских учебных заведениях. Итогом встреч было подписание соглашения о межпарламентским сотрудничестве с Милли Меджлисом Азербайджана.

Через небольшой промежуток времени в Азербайджане прошли Дни культуры Северной Осетии, делегацию возглавил заместитель министра культуры Республики, заслуженный артист РФ Эльбрус Кубалов. В столице страны с сольным концертом выступил государственный ансамбль танца «Алан» под музыку национального оркестра. Также были организованы выставка современного изобразительного искусства «Искусство Осетии», мастер-классы по народно-сценическому танцу, игре на осетинской гармонике, вокалу, композиции и дирижированию.

В ноябре 2014 года в Костроме были проведены дни культуры Азербайджана под лозунгом «Сколько наций, и все понимают язык дружбы», посвященные Дню Единства. Дни культуры начались с турнира по вольной борьбе, на котором участвовало молодое поколение из Владимирской, Вологодской, Тверской, Ивановской, Кировской, Московской областей, Республики Коми, Гагаузии, Костромы и Костромской области. Боевые виды спорта в Азербайджане традиционно являются самыми популярными. По завершению спортивных мероприятий состоялся круглый стол на тему «Взаимоотношения между Азербайджаном и Костромской областью: история и современность. Роль азербайджанцев в истории России и Костромской области». Примечательно, что в фойе была организована книжная выставка, стол с национальными блюдами Азербайджана. Экскурсоводы с радо- 
стью рассказывали костромчанам об Азербайджане. К этому празднику был подготовлен концерт, на котором выступил духовой оркестр памяти Муслима Магомаева, а также заслуженные артисты Костромы и России.

В октябре 2015 года в Самарской области были проведены Дни культуры Азербайджана, организаторами мероприятий были Министерство культуры и молодежной политики Самарской области и агентство по культуре и кинематографии Российской Федерации. В областном художественном центре Самары был проведен вечер кино, где были показаны картины «Сон», «Там, где сливаются реки» и «Возвращение в будущее». В художественном музее была проведена выставка «Орнаменты, берущие начало из Кобустана», уникальная коллекция азербайджанских ковров, изделий прикладного искусства, музыкальных инструментов были показаны в Кусково. Отдельно стоит отметить привлекшие внимание посетителей ковры азербайджанских мастеров, всемирно признанные одними из лучших ворсовые изделия таких азербайджанских школ, как Карабах, Куба, Ширван, Баку, Гянджа, Газах, Тебриз.

В 2016 году в Третьяковской галерее прошла выставка, посвящённая азербайджанским художникам. На выставке было представлено 50 картин 12 художников Апшеронской школы живописи и скульптуры [В Третьяковской галерее..., 2016]. На выставке были продемонстрированы работы Т. Нариманбекова, Д. Мирджавадова, Т. Джавадова. Картины были предоставлены Третьяковской галереей и привезены из Азербайджана.

В октябре 2017 года в столице Азербайджана в г. Баку совместно с Объединением фотографов Азербайджана и Представительством Россотрудничества в Азербайджане состоялась фотовыставка почетного члена Объединения фотографов Азербайджана С. Комковой «Ты меня зовешь, Азербайджан!».

В 2018 году в г. Баку состоялось открытие обновленного Центра русской культуры при Русской общине Азербайджана [Директор Центра..., 2018]. Данный центр функционирует с мая 1993 года. Целью центра является развитие, защита и познание русского языка, литературы и традиций. В центре было организовано более 500 мероприятий, таких как литературные и музыкальные вечера, посвящённые русским и азербайджанским писателям, поэтам, композиторам. В центре организуется празднование Пасхи, Масленицы. В центре функционируют ансамбли «Играй, гармонь» и «Нежность», танцевальная студия, детские коллективы и детский кукольный театр. На основе изложенного можно твердо заявить, что Центр укрепляет межкультурное взаимодействие азербайджанского и русского народов.

В 2019 году в стенах Государственной Думы Российской Федерации при непосредственном участии Центра российско-азербайджанской дружбы, работающего при межпарламентской группе дружбы Россия - Азербайджан, был организован круглый стол «Культурные мосты между Россией и Азербайджаном как основа для межкультурного диалога». На организованном мероприятии при участии видных деятелей азербайджанской и российской культур были озвучены предложения по интенсификации более тесного сотрудничества в гуманитарном секторе взаимодействия стран. Отдельной темой была определена возможность создания и укрепления общего информационного пространства. Дополнительно в ходе совещания была отмечена важность освещения различных культурных и молодежных событий при помощи виртуальных источников информации, таких как средства массовой информации и социальные сети. Данное решение было направлено на молодежь, проводящую много времени во всемирной паутине.

Известно, что ковроделие - это один из традиционных видов декоративноприкладного искусства Азербайджана. При поддержке Московского бюро ЮНЕСКО был выпущен диск под названием «азербайджанские ковры». Традиционное искусство тканья азербайджанских ковров в Азербайджане было внесено в репрезентативный список ЮНЕСКО по нематериальному культурному наследию человечества. В феврале 2020 года в Музее Востока в столице России в г. Москве прошла выставка под названием «Эхо советского Азербайджана» [Выставка «Эхо советского Азербайджана», 2020]. На выставке 
были представлены работы мастеров двадцатого века. На выставке было множество работ, среди которых были такие ковры, на которых размещались отрывки трудов восточных творцов литературы и канонические суры. Не менее интересным явлением были также портретные ковры. В Советском Азербайджане ткали ковры с изображением известных деятелей не только Советского Союза, но и известных зарубежных представителей. Делались ковры с изображением политических деятелей В.И. Ленина и И.В. Сталина.

Немаловажным направлением является здравоохранение. Еще общенациональный лидер Азербайджана Гейдар Алиев, а до этого член Политбюро ЦК КПСС и первый заместитель председателя Совета Министров СССР, сделал ряд важнейших шагов, которые оказали существенное значение для развития инновационной медицины в СССР [Алиев, 2000]. Благодаря Г.А. Алиеву в 1986 году был одобрен проект, на основе которого впоследствии был создан научно-технический комплекс «Микрохирургия глаза». Не менее существенным был вклад азербайджанского политика в советскую и российскую медицину, связанную с кардиологией. Благодаря его непосредственной поддержке молодой и талантливый хирург-кардиолог Р. Акчурин смог организовать научно-исследовательский центр кардиохирургии. Примечательно, что именно Р. Акчурин произвел успешную операцию на открытом сердце первого президента Российской Федерации Бориса Ельцина. Конечно, глава Азербайджана Гейдар Алиев внес немалый вклад в развитие здравоохранения в стране. Данные традиции сохранились и в настоящее время - молодые специалисты, азербайджанские врачи проходят стажировки в российских клиниках и обучаются во всемирно признанных профессиональными российских медицинских академиях. Между врачами двух стран регулярно проводятся круглые столы, на которых специалисты обсуждают проблемы разного рода заболеваний и современных методов их лечения, возможностей проведения совместных операций, обмена опытом и поддержки дружественных во врачебной среде отношений. Из таких встреч можно отметить заседания, посвященные инфекционным заболеваниям, организуемые в Москве НИИ пульмонологии РАН и Российско-респираторным обществом.

Не менее важное место в гуманитарных связях двух стран занимает литература. Произведения таких великих писателей и поэтов, как В.В. Маяковский, С.А. Есенин, А.С. Грибоедов, Х. Ширвани, Н. Гянджеви, Н. Туси, Х. Натаван до сих пор очень популярны как в Азербайджане, так и в России. Так, например, трилогия современного азербайджанского писателя Кямала Абдуллы «Под сенью Карагача» была по достоинству отмечена российскими экспертам, в частности, Георгий Пряхин ни много ни мало поставил данное произведение в один ряд с лучшими произведениями мировой литературы, рекомендуя ее к обязательному прочтению русскому читателю [Пряхин, 2015]. Летом 2016 года в Дагестане был организован автопробег, посвященный 93-летию Р. Гамзатова, где флаги двух стран гордо веяли в унисон с праздником, показывая, как близки два государства в своих связях. В рамках Московской международной книжной выставки-ярмарки прошел уже XIII Международный конкурс государств-участников СНГ «Искусство книги», постоянным участником которого является и Азербайджан [Лебедев, 2009]. На XIII съезде азербайджанские писатели получили семь премий в номинациях «Содружество», «Диалог культур» и «Арт-книга». В соответствии с государственной доктриной в Азербайджане традиционно продолжают интересоваться российской литературой, в частности, по инициативе фонда Гейдара Алиева и министерства культуры Азербайджана в современном Бакинском центре Гейдара Алиева были проведены мероприятия, посвященные 200-летию Михаила Лермонтова, который очень полюбил Азербайджан в ходе своего непродолжительного визита в Баку в 1837 году, где и записал азербайджанскую версию «Ашик-Гариб» совместно с Фатали Ахунзаде. На мероприятии звучало произведение Эдуарда Артемьева «Ангел».

26 марта 2015 года в Екатеринбурге был проведен литературный вечер «Россия и Азербайджан, поэзия и история» [Преображенская, 2018], проводимый в рамках Указа Президента России В.В. Путина о проведении в Российской Федерации года литературы. 
На мероприятии под красочное слайд-шоу были зачитаны великолепные стихи, поэмы Н. Гянджеви «Хосров и Ширин», стихотворение С. Вургуна об Азербайджане, белорусской поэтессы Е.Я. Лось «О Баку». Целями данного мероприятия стало развитие интереса к национальной литературе, стремление к повышению культурного уровня подрастающего поколения, сближению, взаимопониманию и укреплению дружбы между народами, к диалогу и духовному взаимообогащению.

Укреплению гуманитарных связей способствует и развитие межгосударственного туризма [Гамбаров Т.Р., Пахомова А.В., 2016, с. 82-87]. Прошедший 2019 год запомнился положительной динамикой в данном направлении, этому способствовали немногие ключевые причины. Временное закрытие в 2016-2017 годах турецких курортов для российских туристов, привыкших к высокому уровню турецкого сервиса при минимальных ценах на берегу вечно солнечного Средиземного моря, стало настоящим фиаско. Как результат - перераспределение туристических потоков на поиски новых направлений. И одним из них стал Азербайджан, обладающий большим потенциалом в данном направлении, когда от берегов Каспийского моря до вечно заснеженных горнолыжных склонов Шахдага всего 3 часа езды, низкие цены ввиду снижения курса национальной валюты - маната, упрощенный безвизовый режим сделали поездки более доступными и привлекательными. Немаловажным фактором стал и довод близости культур двух стран, наличие широко распространенного русского языка в Азербайджане, что делало путешествие в страну Огней для российских туристов более интересным, непринужденным и запоминающимся. Все эти факторы способствовали и открытию дополнительных новых рейсов из России в Азербайджан и обратно, например, «Уральские авиалинии» открыли авиарейс Габала Москва - Габала, что сделало прилет в один из красивейших городов Азербайджана наиболее простым для туристов, у которых раньше не было альтернативы, кроме как прилет через Баку. «Комиавиатранс» получил допуск на совершение полетов в Баку из Нижнего Новгорода, Самары и Калуги. Так, по данным Бюро по туризму Азербайджана, количество российских туристов, которые в 2019 году посетили страну, составило более 930 тысяч человек [Бюро по туризму Азербайджана, 2020]. Все эти факторы, конечно, помогают россиянам узнать больше об Азербайджане, о его культуре и традициях, что, естественно, положительно отразится в будущем на двухсторонних отношениях между народами.

Подводя итог обзору гуманитарных связей между Азербайджаном и Россией, следует отметить, что в период сложных политических и экономических волнений надежным способом поддержки добрых и крепких отношений остается обычный человеческий фактор, азербайджанский и российский народы подтверждают эту парадигму делом, укрепляя свои связи из года в год и открывая новые горизонты для взаимного сотрудничества. Но тем не менее всего этого могло бы и не быть, если бы не теплые и дружественные связи между государственными аппаратами двух стран и их лидеров в частности. Тем не менее работы остается еще много, ведь нет предела совершенству, а учитывая тот потенциал, каким обладают два государства в области гуманитарных связей, останавливаться нельзя и, используя все доступные методы, нужно укреплять достигнутые успехи и реализовывать поставленные задачи. Учитывая же историю взаимоотношений, можно с уверенностью заявить, что перспектива очевидна и вопрос реализации проектов не заставит себя долго ждать в будущем.

\section{Список литературы}

1. Агабалаева С.А. 2018. Роль журнала «Азербайджан» в повышении художественноэстетического познания народа. Ученые записки Орловского государственного университета. Серия: гуманитарные и социальные науки. 1(78): 58-62.

2. Адыгезалов Г.В. 2008. «Литературный Азербайджан» о связях А.С. Грибоедова с Азербайджаном (современный взгляд на проблему). Научная мысль Кавказа, 34: 70-75. 
3. Алиева-Мамедова Г. 2016. Азербайджан в начале XXI века. Гилея: Научный вестник, 110 (7):150-152.

4. Алиева 3.М. 2015. Россия и Азербайджан: перспективы развития торговоэкономических отношений. Via scientiarum - дорога знаний, 3: 64-68.

5. Алиев Т.Г. 2008. Важнейшие факторы развития внешнеторговых связей между Азербайджаном и Россией. Региональная экономика: теория и практика, 4: 22-27.

6. Алиев Т.Г. 2017. Направления улучшения внешнеторговых связей между Азербайджаном и Россией. International journal of innovative technologies in economy, 3: 10-12.

7. Бюро по туризму Азербайджана. 2020. URL: http://www.tourbus.ru/news/15723.html.

8. Визит В.В. Жириновского в Баку. 2014. URL: https://www.youtube.com/watch?v=qlsIvg3bmHA.

9. В Третьяковской галерее открылся вернисаж «Созвездие Апшерона». 2016. URL: https://vestikavkaza.ru/news/V-Tretyakovskoy-galeree-otkrylsya-vernisazh-Sozvezdie-Apsherona.html.
10. Выставка
Эхо советского
Азербайджана.
2020.
URL: https://www.youtube.com/watch?v=eqKKjVhR2io.

11. Воронина Т.В. 2011. Развитие интеграционного сотрудничества между Россией и Азербайджаном в рамках СНГ. Вестник Ростовского государственного экономического университета, 1: 112-121.

12. Гасанов О.С., Рыжов И.В. 2017. Современное состояние российско-азербайджанских отношений. URL: http://www.nbpublish.com/library_read_article.php?id=22701.

13. Декларация о дружбе и стратегическом партнерстве между Азербайджанской Республикой и Российской Федерацией. URL: kremlin.ru/supplement/250.

14. Дни Дагестана в Азербайджане - выставка, потрясающий концерт. URL: https://www.trend.az > TrendLife.

15. Дни культуры Азербайджана в Костроме. URL: fnkaa.ru/дни-культуры-Азербайджанав-Костроме.

16. Директор Центра русской культуры Азербайджана Галина Манафова: Не мыслю жизни без Баку. 2018. URL: https://moscowbaku.ru/news/culture/direktor_tsentra_russkoy_kultury_azerbaydzhana_galina_manafova_ne_myslyu_zhizni_bez_baku.

17. Информация о VI Международном конкурсе «Искусство книги» государств - участников Содружества Независимых Государств. URL: http://www.cis.minsk.by/page.php?id=15374.

18. Мирзазаде Л.Ф. 2018. Фактор взаимодействия культур в политической стратегии: Азербайджан - Россия. Paradigmata poznani, 3: 52-55.

19. Мустафаева Р.С. 2015. Россия - Азербайджан: роль диаспор в развитии культурногуманитарного сотрудничества. Вестник научной ассоциации студентов и аспирантов исторического факультета Пермского государственного гуманитарно-педагогического университета. Серия: stadia historica jenium, 1: 99-101.

20. Мустафаева Р.С. 2016. Россия - Азербайджан: законодательная база СНГ в культурногуманитарной области. Вестник научной ассоциации студентов и аспирантов исторического факультета пермского государственного гуманитарно-педагогического университета. Серия: stadia historica jenium, 1: 184-195.

21. Национальный состав России URL: http://www.statdata.ru/nacionalnyj-sostav-rossii.

22. Пахомова А.В., Гамбаров Т.Р. 2016. Сравнительный анализ потоков и факторы развития туризма в России в Республике Азербайджан. Актуальные проблемы экономики и менеджмента, 1: 82-87.

23. Пряхин Г. У меня в душе всегда жива добрая, теплая память о Баку. URL: https://www.trend.az/life/interview/2474925.html.

24. Рагимов Р. 2018. Рост курса русскоязычного обучения в Азербайджане: неполноценность, возможность или вызов? Евразийский ежедневный мониторинг, 201.

25. Речь Президента Азербайджана Гейдара Алиева на церемонии открытия памятника гениальному русскому поэту А.C. Пушкину. URL: http://lib.aliyev heritage.org/ru/8191391.html.

26. Смирнов Д.О. 2013. Россия - Азербайджан: направления и перспективы партнерства. Вестник МНЭПУ, 6: 25-29.

\section{References}

1. Agabalayeva S.A. 2018. Rol zhurnala «Azerbaydzhan» v povyshenii khudozhestvennoesteticheskogo poznaniya naroda. Uchenyye zapiski Orlovskogo gosudarstvennogo universiteta. Seriya: 
gumanitarnyye i sotsialnyye nauki [The role of the Azerbaijan magazine in enhancing the artistic and aesthetic knowledge of the people. Scientific notes of Orel state university. Series: humanitarian and social sciences]. 1(78): 58-62 (in Russian).

2. Adygezalov G.V. 2008. «Literaturnyy Azerbaydzhan» o svyazyakh A.S. Griboyedova s Azerbaydzhanom (sovremennyy vzglyad na problemu). Nauchnaya mysl Kavkaza [«Literary Azerbaijan» about A.S. Griboedov with Azerbaijan (modern view of the problem). Scientific thought of the Caucasus]. 34: 70-75 (in Russian).

3. Aliyeva-Mamedova G. 2016. Azerbaydzhan v nachale XXI veka. Gileya: Nauchnyy vestnik [Azerbaijan at the beginning of the XXI century. Scientific Herald]. 110 (7): 150-152 (in Russian).

4. Aliyeva Z.M. 2015. Rossiya i Azerbaydzhan: perspektivy razvitiya torgovoekonomicheskikh otnosheniy. Via scientiarum - doroga znaniy [Russia and Azerbaijan: prospects for the development of trade and economic relations. Via scientiarum - knowledge road]. 3: 64-68 (in Russian).

5. Aliyev T.G. 2008. Vazhneyshiye faktory razvitiya vneshnetorgovykh svyazey mezhdu Azerbaydzhanom i Rossiyey. Regionalnaya ekonomika: teoriya i praktika [The most important factors in the development of foreign trade relations between Azerbaijan and Russia. Regional economy: theory and practice]. 4: 22-27 (in Russian).

6. Aliyev T.G. 2017. Napravleniya uluchsheniya vneshnetorgovykh svyazey mezhdu Azerbaydzhanom i Rossiyey [Directions for improving foreign trade relations between Azerbaijan and Russia]. International journal of innovative technologies in economy. 3: 10-12 (in Russian).

7. Byuro po turizmu Azerbaydzhana [Azerbaijan Tourism Bureau]. 2020. URL: http://www.tourbus.ru/news/15723.html (in Russian).

8. Vizit V.V. Zhirinovskogo v Baku 2014 [Visit V.V. Zhirinovsky to Baku 2014]. URL: https://www.youtube.com/watch?v=qlsIvg3bmHA (in Russian).

9. V Tretiakovskoy galereye otkrylsya vernisazh «Sozvezdiye Apsherona» [In the Tretyakov Gallery opened the vernissage «Constellation Absheron»]. 2016. URL: https://vestikavkaza.ru/news/VTretyakovskoy-galeree-otkrylsya-vernisazh-Sozvezdie-Apsherona.html (in Russian).

10. Vystavka Ekho sovetskogo Azerbaydzhana [Exhibition Echo of Soviet Azerbaijan]. 2020. URL: https://www.youtube.com/watch?v=eqKKjVhR2io (in Russian).

11. Voronina T.V. 2011. Razvitiye integratsionnogo sotrudnichestva mezhdu Rossiyey i Azerbaydzhanom v ramkakh SNG. Vestnik Rostovskogo gosudarstvennogo ekonomicheskogo universiteta [The development of integration cooperation between Russia and Azerbaijan within the CIS. Bulletin of the Rostov State University of Economics]. 1: 112-121 (in Russian).

12. Gasanov O.S. Ryzhov I.V. 2017. Sovremennoye sostoyaniye rossiysko-azerbaydzhanskikh otnosheniy [The current state of Russian-Azerbaijani relations]. URL: http://www.nbpublish.com/library_read_article.php?id=22701 (in Russian).

13. Deklaratsiya o druzhbe i strategicheskom partnerstve mezhdu Azerbaydzhanskoy Respublikoy i Rossiyskoy Federatsiyey [Declaration of friendship and strategic partnership between the Republic of Azerbaijan and the Russian Federation]. URL: kremlin.ru/supplement/250 (in Russian).

14. Dni Dagestana v Azerbaydzhane - vystavka. potryasayushchiy kontsert [Days of Dagestan in Azerbaijan - an exhibition, a stunning concert]. URL: https://www.trend.az >TrendLife (in Russian).

15. Dni kultury Azerbaydzhana v Kostrome [Days of Culture of Azerbaijan in Kostroma]. URL: fnkaa.ru/dn-culture-Azerbaijan-in-Kostrome (in Russian).

16. Direktor Tsentra russkoy kultury Azerbaydzhana Galina Manafova: Ne myslyu zhizni bez Baku [Director of the Center for Russian Culture of Azerbaijan Galina Manafova: I can not imagine life without Baku]. 2018. URL: https://moscowbaku.ru/news/culture/direktor_tsentra_russkoy_kultury_azerbaydzhana_galina_manafova_ne _. myslyu_zhizni_bez_baku/.(in Russian).

17. Informatsiya o VI Mezhdunarodnom konkurse «Iskusstvo knigi» gosudarstv - uchastnikov Sodruzhestva Nezavisimykh Gosudarstv [Information on the VI International Competition «Art of the Book» of the States Parties to the Commonwealth of Independent States]. URL: http: //www.cis.minsk.by/page.php? Id = 15374 (in Russian).

18. Mirzazade L.F. 2018. Faktor vzaimodeystviya kultur v politicheskoy strategii: Azerbaydzhan - Rossiya [The factor of interaction of cultures in political strategy: Azerbaijan - Russia]. Paradigmata poznani, 3: 52-55 (in Russian).

19. Mustafayeva R.S. 2015. Rossiya - Azerbaydzhan: Rol diaspor v razvitii kulturnogumanitarnogo sotrudnichestva. Vestnik nauchnoy assotsiatsii studentov i aspirantov istoricheskogo fakulteta Permskogo gosudarstvennogo gumanitarno-pedagogicheskogo universiteta [The role of diaspo- 
ras in the development of cultural and humanitarian cooperation. Bulletin of the scientific association of students and postgraduates of the historical faculty of Perm state humanitarian-pedagogical university. Series: stadia historica jenium]. 1: 99-101 (in Russian).

20. Mustafayeva R.S. 2016. Rossiya - Azerbaydzhan: Zakonodatelnaya baza SNG v kulturnogumanitarnoy oblasti. Vestnik nauchnoy assotsiatsii studentov i aspirantov istoricheskogo fakulteta permskogo gosudarstvennogo gumanitarno-pedagogicheskogo universiteta. Seriya: stadia historica jenium [Russia-Azerbaijan: The legislative base of the CIS in the cultural and humanitarian field. Bulletin of the scientific association of students and postgraduates of the historical faculty of perm state humanitarian-pedagogical university. Series: stadia historica jeniu]. 1: 184-195 (in Russian).

21. Natsionalnyy sostav Rossii [National composition of Russia]. URL: http: //www.statdata.ru/nacionalnyj-sostav-rossii (in Russian).

22. Pakhomova A.V.. Gambarov T.R. 2016. Sravnitelnyy analiz potokov i faktory razvitiya turizma v Rossii v Respublike Azerbaydzhan. Aktualnyye problemy ekonomiki i menedzhmenta [Comparative analysis of flows and factors in the development of tourism in Russia in the Republic of Azerbaijan. Actual problems of economics and management]. 1: 82-87 (in Russian)

23. Pryakhin G. U menya v dushe vsegda zhiva dobraya, teplaya pamyat o Baku [A kind, warm memory of Baku is always alive in my soul - a writer]. URL: https://www.trend.az/life/interview/2474925.html (in Russian).

24. Ragimov R. 2018. Rost kursa russkoyazychnogo obucheniya v Azerbaydzhane: nepolnotsennost. vozmozhnost ili vyzov? Evraziyskiy ezhednevnyy monitoring [Rising Profile of Russian-Language Schooling in Azerbaijan: Inferiority, Opportunity or Challenge? Eurasia Daily Monitor]. 201 (in English).

25. Rech Prezidenta Azerbaydzhana Geydara Aliyeva na tseremonii otkrytiya pamyatnika genialnomu russkomu poetu A.S. Pushkinu [Speech of President of Azerbaijan Heydar Aliyev at the opening ceremony of the monument to the genius Russian poet Alexander Pushkin]. URL: http: //lib.aliyev heritage.org/ru/8191391.html (in Russian).

26. Smirnov D.O. 2013. Rossiya - Azerbaydzhan: napravleniya i perspektivy partnerstva. Vestnik MNEPU [Russia - Azerbaijan: directions and prospects for partnership. Vestnik MNEPU]. 6: 25-29 (in Russian).

\section{Ссылка для цитирования статьи Link for article citation}

Бородина М.Ю., Гасанов О.С. 2020. Гуманитарные аспекты сотрудничества России и Азербайджана в XXI веке. Via in tempore. История. Политология, 47 (2): 427-436. DOI 10.18413/2687-0967-2020-47-2-427-436.

Borodina M.U., Gasanov O.S. 2020. Humanitarian aspects of cooperation between Russia and Azerbaijan in the 21st century. Via in tempore. History and political science, 47 (2): 427-436 (in Russian). DOI 10.18413/2687-0967-2020-47-2-427-436. 